\title{
As áreas do conhecimento na pós-graduação stricto sensu brasileira: crescimento longitudinal entre 1995 e 2014
}

Caroline Lievore ${ }^{a}$ Claudia Tania Picinin a Luiz Alberto Pilatti a

\section{Resumo}

O objetivo desta pesquisa foi mensurar o crescimento das áreas do conhecimento na pós-graduação nacional entre 1995 e 2014. Os dados foram coletados no Sistema de Informações Georreferenciadas da Capes (GeoCapes). Utilizaramse como variáveis de estudo: (i) distribuição de programas de pós-graduação por áreas do conhecimento; (ii) distribuição de docentes de pós-graduação; (iii) distribuição de discentes e (iv) investimentos em bolsas e fomento. Os resultados apontaram que as áreas do conhecimento que apresentaram o maior número de programas de pós-graduação foram a Interdisciplinar, as de Ciências Agrárias e a de Educação. As áreas com maior crescimento percentual foram as de Ensino, Biodiversidade e Interdisciplinar. Áreas como Medicina III e Ciências Biológicas tiveram o número de programas reduzidos. Filosofia, Astronomia e Química apresentaram o maior número de docentes vinculados por programa de pós-graduação, no entanto, não formaram o maior número de mestres e doutores.

Palavras-chave: Programas de pós-graduação. Áreas do conhecimento. Docentes e discentes de pós-graduação.

\section{Introdução}

O Brasil apresentou uma crescente participação na produção científica mundial nas últimas décadas, ocupando a $13^{\mathrm{a}}$ posição no ranking mundial e alcançando $2 \%$ da produção de artigos científicos indexados. Conforme levantamento

\footnotetext{
a Universidade Tecnológica Federal do Paraná - UTFPR. Curitiba, Paraná, Brasil. 
feito pela empresa Thomson Reuters, entre 1993 e 2013, o Brasil galgou onze posições no ranking mundial. Em termos percentuais, isso significa um aumento de $700 \%$ nesse período. Contudo, a China, que também é considerada um país em desenvolvimento, aumentou sua produção em $2.292 \%$, subindo da $15^{\mathrm{a}}$ posição, em 1993, para a $2^{\mathrm{a}}$ posição, em 2013. Já a Coreia do Sul, que em 1993 não aparecia na lista dos vinte e cinco países mais produtivos em ciência, em 2013 surge na 12a posição. Embora com um ritmo mais lento que a China, com crescimento de $112 \%$, os Estados Unidos se mantiveram no topo deste ranking (LEITE, 2014).

Estudos realizados por Almeida e Guimarães (2013) indicam que a produção científica do Brasil atingiu uma taxa de crescimento médio de 10,7\% ao ano, ritmo cinco vezes maior que a média mundial. Este desempenho colocou o Brasil entre os vinte e seis países com uma contribuição individual igual ou superior a $1 \%$ dos artigos no ranking produção mundial. Em conjunto, a produção desses países corresponde a $87 \%$ da produção científica indexada internacionalmente.

Para dar suporte ao crescimento científico nacional, políticas consistentes no campo da Ciência, Tecnologia e Inovação (CT\&I) foram implementadas em nível federal e estadual ao longo de algumas décadas. Na década de 1950, com ações da Coordenação de Aperfeiçoamento de Pessoal de Nível Superior (Capes) e do Conselho Nacional de Desenvolvimento Científico e Tecnológico (CNPq), o Brasil intensificou a formação de mestres e doutores e o apoio mais intenso à pesquisa científica (MORITZ et al., 2013).

Uma década depois, por meio do Parecer $n^{\circ}$ 977/1965, instituiu-se, de maneira formal, os cursos de pós-graduação no Brasil, enfatizando-se a distinção entre a pós-graduação lato sensu e a stricto sensu. Pela primeira, define-se os cursos de especialização e aperfeiçoamento, enquanto que a pós-graduação, em sentido restrito, delibera o "sistema de cursos que se superpõe à graduação com objetivos mais amplos e aprofundados de formação científica ou cultural" (BRASIL, 1965, p. 4).

Esses surgiram da necessidade de espaços especializados em fomentar avanços na área científica e tecnológica e adequar à nova concepção de universidade. Neste período, houve uma crescente demanda social por qualificação e estímulo da pesquisa nacional, tornando a pós-graduação uma consequência natural do progresso do conhecimento em todas as áreas (BOMENY, 2001).

De forma estratégica, a pós-graduação ${ }^{1}$ atua no desenvolvimento científico do País e é marcada por um rigoroso sistema de avaliação e reconhecimento dos

1 O vocábulo pós-graduação utilizado nesta pesquisa, refere-se apenas à pós-graduação stricto sensu. 
seus Programas de Pós-Graduação (PPG). Tal sistema é dividido basicamente em dois processos distintos: entrada e permanência destes programas. Os resultados dessas avaliações são apresentados de forma quantitativa para a comunidade acadêmica e organizados por áreas do conhecimento por meio de Relatórios trienais e Documentos de Área. Esses documentos servem de base para avaliações de novos cursos, além de assegurar e manter a qualidade dos cursos de Mestrado e Doutorado no País. Todos os Documentos de Área descrevem o estado vigente, características, perspectivas e quesitos considerados prioritários na avaliação dos PPG pertencentes a cada área. Para organizar esses processos, a Capes definiu uma hierarquização das áreas do conhecimento que são subdivididas por critério de afinidade em dois níveis (Colégios e Grandes Áreas). Os três Colégios abrangem as nove grandes áreas, as quais se distribuem em 48 áreas de avaliação (BRASIL, 2016).

Todo o planejamento estratégico do sistema brasileiro de pós-graduação é conduzido pelos Planos Nacionais de Pós-Graduação (PNPG), criados em 1975 e fundamentais durante o percurso desse complexo processo educacional. Entre o I Plano 1975-1979 e o VI Plano 2011-2020 (vigente), a Capes buscou organizar seus processos, métodos e avaliações elevando a qualidade do sistema nacional de pós-graduação a um patamar competitivo e influenciando o crescimento da pós-graduação no Brasil. As práticas e processos estabelecidos em cada um dos PNPG criaram um ambiente de políticas e fomentos, iniciando um processo de mudanças importantes, a fim de colocar o Brasil em condições de acompanhar países mais desenvolvidos.

Analisando os caminhos percorridos pelo sistema de pós-graduação no Brasil, especialmente pelas áreas que compõem este sistema, o objetivo deste artigo ateve-se em mensurar o crescimento longitudinal das áreas do conhecimento da Capes, no período entre 1995 e 2014, em relação à: (1) distribuição dos programas de pós-graduação por área do conhecimento; (2) distribuição de vínculos docentes da pós-graduação por área do conhecimento; (3) distribuição de discentes na pós-graduação em cada área do conhecimento e aos (4) investimentos realizados pela Capes em bolsas e fomento em cada área do conhecimento.

Com a perspectiva de entender as áreas do conhecimento que compõem a pós-graduação nacional, esta pesquisa justifica-se por expor de forma sistemática o quanto cada área se desenvolveu no período entre 1995 e 2014 com relação as variáveis propostas. O crescimento e a consolidação das áreas do conhecimento na pós-graduação geram produtos diretos, como a pesquisa científica e a produção de conhecimentos, contribuindo diretamente para o desenvolvimento social da nação. 


\section{A influência dos planos nacionais nos programas de pós-graduação}

O Brasil passa por um período de maior amplitude e valorização do sistema de pós-graduação, que se consolidou por possuir alta qualificação nacional e internacional. São nítidos os avanços, destacados em editoriais, revistas, fóruns e organismos internacionais, alcançados nos últimos anos na ciência e tecnologia nacionais, comprovados, entre outros indicadores, pela $13^{\mathrm{a}}$ posição na produção científica mundial (LEITE, 2014).

O crescimento da ciência nacional está intimamente ligado à relevância da pós-graduação para a produção de conhecimento, uma realidade das últimas décadas, legitimada internamente e reconhecida internacionalmente. Para Barreto e Borges (2009), a pós-graduação é o setor educacional brasileiro com maior desempenho e que teve, ao longo de décadas, o planejamento de médio e longo prazos, além de uma permanente participação da comunidade científica nacional.

Esse resultado positivo se deve, sobretudo, ao rigoroso processo de avaliação realizado pela Capes (MORITZ et al., 2013). O modelo de avaliação utilizado no Brasil aplicado a todas as áreas do conhecimento, segue as experiências das instituições de ensino superior dos Estados Unidos. Porém, nos últimos anos, a Capes centrou seu processo de avaliação na produção científica de cada programa. Para cada área do conhecimento, a agência formou comitês compostos por renomados pesquisadores responsáveis por avaliar e classificar todos os programas pertencentes a sua área (BALBACHEVSKI, 2005).

Almeida e Guimarães (2013) citam que o crescimento da produção científica no Brasil se correlaciona diretamente com o desenvolvimento dos PNPG. Sob responsabilidade da Capes, os PNPG, que sintetizam políticas públicas para qualificação em nível de mestrado e doutorado. Nos Planos são propostas diretrizes, estratégias e metas para o sistema, com o objetivo de alavancar a ciência e a tecnologia.

O I Plano (1975-1979) apresentou como principal objetivo a capacitação dos docentes universitários, formando o primeiro contingente de pesquisadores e especialistas em território nacional. Para Hostins (2006), além da capacitação dos docentes, destaca-se a integração da pós-graduação ao sistema universitário, a valorização das ciências básicas e a necessidade em se evitar assimetrias regionais. O II Plano (1982-1985), além do objetivo anterior, teve como ênfase despertar os pesquisadores para a qualidade e seu desempenho, por meio de 
avaliações aperfeiçoadas na pós-graduação. Segundo Kuenzer e Moraes (2005), este Plano enfatizou a qualidade do ensino de graduação e de pós-graduação, tornando prioritários a institucionalização e o aperfeiçoamento da avaliação, que já existia de forma embrionária, desde 1976.

O III Plano (1986-1989) foi introduzido em uma nova era política do País, quando José Sarney (1985-1990) assumiu a presidência após o fim da ditadura militar, caracterizando a democratização política do Brasil e sua estabilização econômica. Este Plano propôs a integração da pesquisa universitária com o setor produtivo, visando ao desenvolvimento nacional. Segundo Hostins (2006), ao longo dos anos de 1980, foram feitos investimentos na estruturação e no aperfeiçoamento do sistema de avaliação dos programas, com a progressiva informatização e aprimoramento dos relatórios que visavam à geração de indicadores.

Entre 1990 e 1998, a Capes não formalizou um Plano Nacional do sistema de pós-graduação, no entanto, fatos importantes ocorreram nesse período. Em 1995, criou-se no País o Mestrado Profissional, instituído por meio da Portaria Capes $\mathrm{n}^{\circ}$ 47/1995 e, mais tarde, revogada pela Portaria ${ }^{\circ}$ 80/1998 (BRASIL, 1998). Segundo Avila et al. (2009), o principal argumento usado para sua criação foi a flexibilização que o programa prometia, visando acatar as demandas do mercado capitalista, dentro da estrutura universitária, especificamente no nível da pós-graduação.

O IV PNPG, que estabeleceria os parâmetros da política de pós-graduação entre 1998 e 2002, não se efetivou como documento oficial, por não apresentar, entre outras restrições, viabilidade orçamentária. Apesar de o documento não ter sido formalizado, não impediu que a Capes colocasse em prática as propostas criadas neste Plano, especialmente em relação ao sistema de avaliação (AVILA et al., 2009; KUENZER; MORAES, 2005).

Neste período (1998-2002), a Capes implementou o novo modelo de avaliação, valorizando prioritariamente a produção científica, o que provocou uma inversão do que havia sido proposto anos antes pelo III PNPG, ou seja, "o deslocamento da centralidade na docência para a centralidade na pesquisa". Além disso, foi introduzida a ideia de programas de pós-graduação ao invés de cursos de mestrado e doutorado avaliados isoladamente, "havendo uma atenção especial às linhas de pesquisa e à sua organicidade com as disciplinas, projetos e produtos de pesquisa, teses e dissertações" (KUENZER; MORAES, 2005, p. 8). Estas alterações serviram de base para o desenvolvimento da pesquisa científica na pós-graduação. 
Como forma de assegurar e manter estes objetivos, em 1998, foi criado o Sistema Nacional de Avaliação da Pós-Graduação, com frequência quadrienal (sendo o primeiro quadriênio vigente 2013-2016, conforme Resolução $n^{\circ}$ 05/2014), orientado pela Diretoria de Avaliação (DAV) da Capes e com a participação da comunidade científica brasileira (BRASIL, 2014). A avaliação é realizada nas quarenta e oito áreas (número vigente em 2014), seguindo a mesma sistemática estabelecida pelo Conselho Técnico Científico da Educação Superior (CTC-ES) e teve como objetivos:

- Certificação da qualidade da pós-graduação Brasileira (referência para a distribuição de bolsas e recursos para o fomento à pesquisa);

- Identificação de assimetrias regionais e de áreas estratégicas do conhecimento no SNPG para orientar ações de indução na criação e expansão de programas de pós-graduação no território nacional (BRASIL, 2016).

Todas as informações referentes à composição da avaliação são apresentadas nos documentos de cada uma das áreas, os quais servem como referência para os processos avaliativos de novos cursos ou para avaliação quadrienal dos cursos que já estão em funcionamento. Nestes documentos são descritos a situação vigente da área, as características, as perspectivas e os itens considerados prioritários na avaliação dos programas de pós-graduação (BRASIL, 2016).

Ainda em 1998, a Capes criou o sistema Qualis, sendo "uma lista com a classificação dos veículos utilizados pelos programas de pós-graduação para a divulgação da sua produção", auxiliando na estratificação da qualidade da produção intelectual dos programas de pós-graduação (BRASIL, 2016). Com o crescimento da produção, houve um aumento no número de revistas científicas nacionais e internacionais avaliadas pelo Qualis. Esse sistema classifica as revistas hierarquicamente, em sete níveis: A1, A2, B1, B2, B3, B4 e B5. Um dos critérios estabelecidos para se alcançar o maior nível é a regularidade da produção para os sites de indexação de periódicos (GUZZO et al., 2015)

O V Plano (2005-2010) teve foco nas políticas estratégicas das atividades de pós-graduação e no aprimoramento da avaliação qualitativa da pós-graduação (conceito de nucleação e revisão do Qualis). Assim como nos demais Planos, o V Plano manteve: a preocupação com as assimetrias regionais e a baixa formação de pesquisadores em regiões menos favorecidas; a ênfase na qualidade e excelência dos resultados, na especificidade das áreas de conhecimento e no impacto dos resultados obtidos pelas pesquisas no meio científico e social. Subentende-se que 
a qualidade da pós-graduação é aferida pela qualidade da produção científica dos grupos de pesquisa que a compõem (BRASIL, 2005).

No final de 2010, em parceria com o CNPq e outras agências de fomento, a Capes apresentou o VI Plano Nacional da pós-graduação com vigência entre 2011 e 2020, elaborado concomitantemente ao novo Plano Nacional de Educação (PNE) do Ministério da Educação (MEC). Conforme o próprio documento da Capes cita, “[...] pela primeira vez, um plano nacional de educação contemplará as propostas de diretrizes e políticas do ensino de pós-graduação, isso porque o PNPG é parte integrante do PNE" (BRASIL, 2010, p. 13). Em nível conceitual, adota-se uma visão sistêmica em suas análises, diretrizes e propostas. Sem esquecer as conquistas e heranças deixadas pelos planos anteriores, o VI Plano propõe estratégias, integrando o contexto científico contemporâneo do Brasil ao mundo.

O fato de este plano ter sido criado em um cenário político positivo e emergente favoreceu a ênfase em determinadas áreas do conhecimento, como o setor agrário. Quando esse plano foi lançado, a agricultura era fomentada por novas tecnologias, por especialistas qualificados e por empresas competitivas, atingindo assim altos níveis de produtividade. Conforme se encontra descrito no VI PNPG, “[...] nas duas últimas décadas a área plantada com grãos aumentou $25 \%$ e a produção aumentou $154 \%$, levando o País a converter-se em verdadeiro celeiro mundial, competindo com os EUA e a Europa" (BRASIL, 2010, p. 17). Outro fato que exemplifica a tendência do VI Plano em promover determinadas áreas do conhecimento foi a descoberta do pré-sal, que exige recursos humanos e recursos de infraestrutura, especialmente nas áreas de Engenharia (BRASIL, 2010).

O VI Plano apresenta também um foco maior em algumas áreas do conhecimento, usando como modelo os Centros Regionais de Competência (CRC), criados em 1991 pelas agências de ensino da Austrália. Seguindo este modelo, a Capes, por meio da Agenda Nacional de Pesquisa, escolheu, a exemplo dos CRC, áreas consideradas prioritárias para o desenvolvimento do País. Estas áreas são: "biotecnologia, fármacos, medicamentos e vacinas, materiais avançados, nanotecnologia, tecnologia da informação e da comunicação, microeletrônica, espaço, defesa e energia nuclear" (BRASIL, 2010, p. 20). Contudo, o foco em determinadas áreas do conhecimento não deve causar prejuízos a outras áreas não priorizadas.

Por meio da Agenda Nacional de Pesquisa, a Capes pretende incorporar as pesquisas multi e interdisciplinares, conduzindo à formação de "novas engenharias institucionais" e à criação de redes de pós-graduação e pesquisa (BRASIL, 2010, p. 19). 
Além do destaque para algumas áreas do conhecimento, a Capes visa, no decênio 2011-2020, estimular o acesso aos programas de doutorado, à semelhança do que se passa nos países mais desenvolvidos (EUA e França), adotando, a longo prazo, processos parecidos. Até o lançamento do VI Plano, em 2010, a pós-graduação nacional formava um número expressivo de doutores nas áreas Humanas, que incluem as Ciências Sociais Aplicadas, Letras, Artes e as Ciências Humanas (cerca de $31 \%$ dos alunos matriculados em doutorados). O bloco que abrange as Ciências da Saúde e as Ciências Biológicas representavam 27\% e as Engenharias, apenas 11\% (BRASIL, 2010). Considerando esses números, uma das propostas do VI Plano refere-se à inclusão do mestrado acadêmico no doutorado. O mestrado acadêmico corresponde a $66,45 \%$ do total de alunos de pós-graduação titulados no Brasil, em 2014, sendo que o ideal seria que estes mestres dessem continuidade a sua qualificação, ingressando no doutorado. Uma das metas do sistema é introduzir o ciclo completo, até o doutorado, ampliando os índices de titulação de doutores brasileiros (GEOCAPES, 2015).

\section{Metodologia}

Para a coleta dos dados foi utilizado o Sistema de Informações Georreferenciadas da Capes (GeoCapes), com a busca abrangendo dados relacionados à pós-graduação stricto sensu, no período entre 1995 e 2014 . A coleta de dados aconteceu entre os meses de setembro e novembro de 2015.

O GeoCapes é uma ferramenta de dados de georreferência que serve para referenciar dados e informações dos índices gerenciados pela Capes no Brasil e no exterior, de acordo com sua localização geográfica.

Para esse estudo, utilizaram-se todas as variações possibilitadas pela ferramenta (gráficos, tabelas, seleção de dados exclusiva para regiões e áreas do conhecimento), com o intuito de extrair informações relevantes para a análise das variáveis que envolvem todas as áreas do conhecimento na pós-graduação nacional, entre 1995 e 2014.

O GeoCapes disponibiliza os seguintes indicadores para consulta, conforme mostra-se no Quadro 1.

Foram realizadas análises sistemáticas de todo País, tendo como foco de estudo as áreas do conhecimento divididas em cada uma das variáveis disponíveis no sistema GeoCapes. Dentre estes indicadores (Quadro 1), foram coletadas e analisadas as informações referentes a: (1) distribuição dos programas de 
pós-graduação; (2) distribuição de discentes de pós-graduação; (3) distribuição de vínculos docentes à pós-graduação; (4) concessão de bolsas de estudo; (5) distribuição de bolsistas de pós-graduação no Brasil e no exterior e (6) investimentos da Capes em bolsas e fomentos.

A coleta de dados supramencionada foi organizada em três grupos de informações, sendo: (1) programas de pós-graduação; (2) docentes e discentes e, (3) bolsas e fomento. Cada um desses grupos foi composto por subvariáveis, de forma a permitir a avaliação adequada, de acordo com os dados fornecidos no GeoCapes, exposto no Quadro 2.

Quadro 1. Indicadores e período da série histórica da GeoCapes.

\begin{tabular}{|l|c|c|c|c|c|}
\hline \multirow{2}{*}{ Indicador } & \multirow{2}{*}{$\begin{array}{c}\text { Período de } \\
\text { abrangência }\end{array}$} & \multicolumn{4}{|c|}{ Nível de visualização } \\
\cline { 5 - 6 } & Município & UF & Brasil & Mundo \\
\hline $\begin{array}{l}\text { Concessão de bolsas da } \\
\text { pós-graduação }\end{array}$ & 1995 a 2014 & X & X & X & - \\
\hline $\begin{array}{l}\text { Distribuição de bolsistas da Capes no } \\
\text { exterior }\end{array}$ & 1998 a 2013 & - & - & - & $X$ \\
\hline Distribuição de discentes & 1998 a 2014 & $X$ & $X$ & $X$ & - \\
\hline $\begin{array}{l}\text { Distribuição de programas de } \\
\text { pós-graduação }\end{array}$ & 1998 a 2014 & $X$ & $X$ & $X$ & - \\
\hline Distribuição de docentes & 1998 a 2014 & $X$ & $X$ & $X$ & - \\
\hline Acesso ao Portal de Periódicos & 2001 a 2014 & $X$ & $X$ & $X$ & - \\
\hline $\begin{array}{l}\text { Investimento da Capes em bolsas e } \\
\text { fomento por Estado (valores em R\$ mil) }\end{array}$ & 2002 a 2012 & - & $X$ & $X$ & - \\
\hline
\end{tabular}

Fonte: GeoCapes (2015).

Quadro 2. Roteiro da coleta de dados.

\begin{tabular}{|l|c|}
\hline Variáveis deste estudo & \multirow{2}{*}{ De 1998 a 2014} \\
\cline { 1 - 1 } 1. Programas de pós-graduação no Brasil & \multirow{2}{*}{ De 1998 a 2014} \\
\cline { 1 - 1 } 1.1 Distribuição dos programas por áreas do conhecimento & \\
\cline { 1 - 1 } 2. Docentes e discentes & \multirow{2}{*}{ De 2002 a 2012} \\
\cline { 1 - 1 } 2.1 Distribuição de vínculos docentes por áreas do conhecimento & \\
\cline { 1 - 1 } 2.2 Distribuição de discentes por áreas do conhecimento & De 1995 a 2014 \\
\hline 3. Bolsas e fomento & De 1998 a 2012 \\
\hline 3.1 Investimentos em bolsas e fomento por áreas
\end{tabular}

Fonte: Elaborado pelos autores (2015). 
Os dados quantitativos coletados, referentes a cada grupo (programas de pós-graduação no Brasil, docentes e discentes, bolsas e fomento), foram tratados por meio de estatísticas descritivas (medidas de tendência central e medidas de dispersão). As variáveis foram comparadas entre si, quanto a sua distribuição por áreas do conhecimento, sendo considerada a média, representatividade e evolução do montante, relacionando ou confrontando as variáveis em cada grupo de informações.

\section{Apresentação de resultados}

\subsection{Programas de pós-graduação no Brasil: distribuição por áreas do conhecimento de 1995 a 2014}

O crescimento quantitativo dos programas de pós-graduação foi observado em várias esferas que compreendem o sistema de ensino no País. No período entre 1998 e 2014, o Brasil passou de 1.259 programas para 3.678 programas de pós-graduação, um crescimento de $192 \%$ no número de programas stricto sensu entre todas as áreas do conhecimento. Até 2014, esses programas eram compostos por 83.930 vínculos de professores e 232.381 alunos matriculados, em que, $49,73 \%$ eram alunos de mestrado acadêmico, $9,45 \%$ de mestrado profissional e $40,82 \%$ alunos de doutorado.

Em 1998, os programas existentes atendiam 45 áreas do conhecimento e, em 2014, as áreas passaram a ser 49. Em 2007, a Capes instituiu mais duas áreas (Materiais e Biotecnologia) e, em 2010, outras duas áreas foram designadas (Ciências Ambientais e Nutrição), obtendo sistemas de avaliação e coordenação exclusivos.

Após verificar o número de programas de pós-graduação em cada área do conhecimento, entre 1998 e 2014, optou-se por selecionar e discutir as dez áreas com maior número de programas, conforme apresentado na Figura 1.

Entre 1998 e 2014, a área Interdisciplinar (que abrange Meio Ambiente e Agrárias; Sociais e Humanidades; Engenharia/Tecnologia/Gestão; Saúde e Biológicas), conforme Documento de Área (BRASIL, 2013a), apresentou o maior número de programas de pós-graduação no País, passando de 34 para 270 programas de pós-graduação. Ciências Agrárias I aparece em seguida com 214 programas em 2014 e um crescimento de 126,37\% entre 1998 e 2014. As Ciências Agrárias I abrangem as subáreas: (1) Agronomia, (2) Recursos Florestais e Engenharia Florestal e (3) Engenharia Agrícola. Apesar do proposto pelo VI PNPG, em que áreas que envolvem o setor agrário teriam prioridades nas políticas de pós-graduação, as Ciências Agrárias I foram a $31^{\circ}$ área em percentual de crescimento, expondo uma discrepância entre as previsões do último plano e o que está sendo realizado. 
Áreas com maior número de programas de pós-graduação entre 1998 e 2014

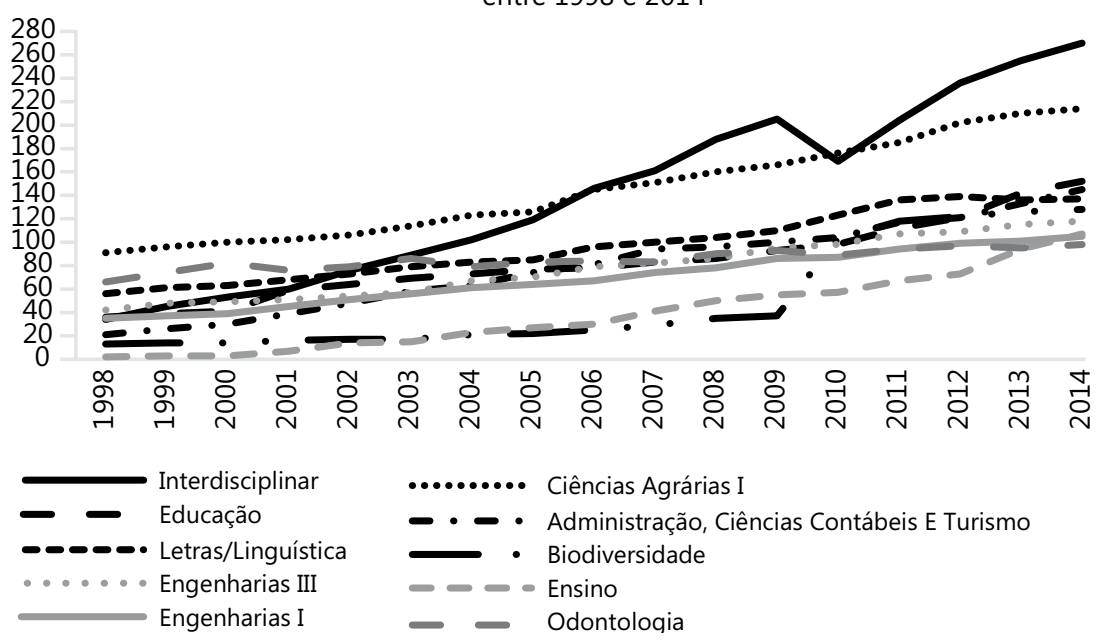

Fonte: GeoCapes (2015).

Figura 1. Dez áreas do conhecimento com maior número de programas de pós-graduação de 1998 a 2014.

A terceira área com maior número de programas de pós-graduação é a Educação, que passou de 36 programas em 1998 para 152, em 2014, crescendo 322,22\%, seguido de Administração, Ciências Contábeis e Turismo com 145 programas, Letras/Linguística com 137 programas em 2014.

Com prioridade no VI PNPG, a Biodiversidade representa a sexta posição, passando de 13 programas em 1998, para 128, em 2014 (crescimento de 884,62\%). As Engenharias III (Engenharia Mecânica, Engenharia de Produção, Engenharia Naval e Oceânica e Engenharia Aeroespacial) e as Engenharias I (Engenharia Civil, Engenharia Sanitária e Engenharia de Transporte) estão em $7^{\circ}$ e $8^{\circ}$ lugar com 118 e 105 programas, respectivamente. Conforme dados do VI PNPG 2011-2020, o País exibe baixa procura de engenheiros por programas de pós-graduação, e isto pode estar associado à crescente demanda destes profissionais no mercado de trabalho.

O Brasil vive hoje uma grande demanda por engenheiros e tecnólogos: não bastasse o déficit na construção civil de 38,5 mil profissionais, com o pré-sal o setor de petróleo e gás deverá contratar mais de 150 mil engenheiros de diferentes especialidades, enquanto outras áreas da tecnologia deverão gerar 100 mil vagas em 2011 e mais 200 mil até 2015 , ao que se devem acrescentar um montante de vagas igualmente 
expressivo para os demais cinco anos cobertos pelo Plano (BRASIL, 2010, p. 21).

Entre as Engenharias, a Engenharia II (Engenharia Química, Engenharia Nuclear, Engenharia de Materiais, Engenharia Metalúrgica e Engenharia de Minas) apresentou o menor crescimento, $118 \%$ e o $34^{\circ}$ lugar entre todas as áreas, passando de 38 para 83 programas de pós-graduação em 2014. A área de Ensino é a nona área em número de programas, sendo que em 1998 contava com apenas dois programas e, em 2014, possuía 107 programas, sendo, portanto, a área do conhecimento que apresentou o maior percentual de crescimento neste período. Em décimo, está a área de Odontologia e a primeira na área da saúde, com um total de 98 programas de pós-graduação e um crescimento percentual de 48,48\%.

Tendo em vista que algumas áreas apresentaram um crescimento significativo na pós-graduação e outras tiveram a evolução foi mais lenta, verificou-se quais obtiveram uma ascensão no período entre 1998 e 2014 (Figura 2) e em quais o crescimento foi menor ou apresentaram queda no número de programas de pós-graduação.

A área de Ensino teve o maior crescimento percentual entre todas as áreas do conhecimento na pós-graduação. Conforme o Documento de Área (2013), o Ensino cresce em ritmo adequado para suprir as demandas e desafios do ensino no Brasil. Pode-se dizer que o crescimento da área de Ensino se deve à forte adesão que a área teve ao Mestrado Profissional. Esta demanda surgiu da Capes

Maior percentual de crescimento entre 1998 e 2014

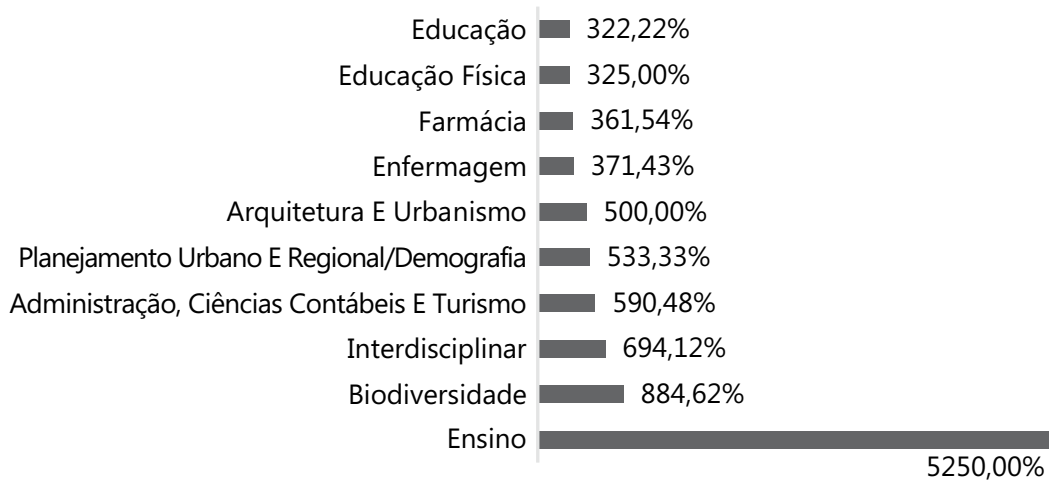

Fonte: GeoCapes (2015).

Figura 2. Áreas com maior percentual de crescimento em número de programas de pós-graduação entre 1998 e 2014. 
com o propósito de qualificar professores da rede pública que estão em serviço, principalmente, os da educação básica. Os Mestrados Profissionais são a maioria na Área (47\%) e geram produtos e processos educacionais para implementação em condições reais nas escolas públicas do País (BRASIL, 2013b).

A Biodiversidade aparece em seguida com crescimento de $884,62 \%$. Conforme seu Documento de Área (BRASIL, 2013c), o Brasil abriga 20\% das espécies existentes e é provedor de importantes serviços ambientais para o planeta. No período entre 2007 e 2009, o Brasil formou em média um doutor por dia em temas ligados à Biodiversidade. No entanto, essa área ainda está carente de tecnologia e pesquisas, visto que o Brasil não dispõe de exploração sustentável e economicamente competitiva dos recursos ligados à biodiversidade.

A terceira área do conhecimento com maior evolução foi a Interdisciplinar que, mesmo sendo reestruturada com a criação das áreas de Materiais e Biotecnologia em 2007 e Ciências Ambientais em 2010 (que antes compunham a área Interdisciplinar), apresentou crescimento de $694,12 \%$, no período mencionado. As áreas de Administração, Ciências Contábeis e Turismo aparecem em seguida com 590,48\% de crescimento. Conforme o Documento de Área dessas (BRASIL, 2013d), este crescimento também se operou de forma qualitativa, visto que houve um aumento expressivo no número de publicações científicas em periódicos internacionais com índices de impacto elevados, especialmente na área de Ciências Sociais Aplicadas.

Conforme já mencionado, existem áreas que não cresceram no período avaliado, ou que o número de programas foi reduzido, como são os casos das áreas de Medicina III e Ciências Biológicas I, apresentados na Figura 3.

Medicina III apresentou queda de 20\% no número de programas de pós-graduação. Em 1998 contava com 50 programas e, em 2014, o número reduziu para 40. Esta área engloba todos os programas de Cirurgia Geral e especialidades cirúrgicas e, conforme seu Documento de Área (BRASIL, 2013e), um dos maiores desafios está em consolidar seus programas de pós-graduação nas regiões Norte e Centro-Oeste, visto que a maior concentração está no Sudeste, especialmente na Universidade de São Paulo (USP). Embora não tenha tido crescimento, a Sociedade Brasileira de Cirurgia Plástica coloca o Brasil como líder mundial em cirurgias desta especialidade. Ao todo, foram 23 milhões de cirurgias plásticas em 2013, ficando à frente até mesmo dos EUA, com pouco mais de um milhão de cirurgias.

Ciências Biológicas I também apresentou queda de 4,92\% no número de programas, sendo que em 1998 eram 61 e, em 2014, o número de programas caiu para 58. 
Segundo o Documento de Área de Ciências Biológicas I (BRASIL, 2013f), no final de 2008, onze programas migraram da área para compor a recém-criada área de Biotecnologia e, em 2011, mais três programas migraram para formar, juntamente com a Ecologia, a área de Biodiversidade. Estas migrações, portanto, justificam a redução no número de programas da área de Ciências Biológicas I.

Apesar de ser uma ciência milenar, a área de Filosofia/Teologia apresentou crescimento de apenas 5,56\%. Em 1998 contava com18 programas e, em 2014, passou a ter 19 programas. Conforme o Documento de Área de Filosofia (2013g), sua prioridade no País era realmente um crescimento qualitativo, com foco na diversidade das pesquisas, impactando diretamente na qualidade das publicações e visibilidade internacional.

Das dez áreas que apresentaram menor percentual de crescimento em programas de pós-graduação no Brasil, cinco estão na grande área Ciências da Saúde, sendo: Nutrição, criada como área em 2010, passou de 16 para 25 programas até 2014, tendo um pequeno crescimento de 56,25\%; Odontologia, que em 1998 contava com 66 programas e, em 2014, possuía 98, crescendo 48,48\%; Medicina II, que passou de 58 programas em 1998 para 86 programas em 2014, com crescimento de 48,28\%; Medicina I, com 51 cursos em 1998 e 87 em 2014, crescendo 70,59\%.

Em geral, das 49 áreas existentes no Brasil, 24,49\% apresentam menos de 50 programas de pós-graduação, $57,14 \%$ possuem entre 50 e 100 programas e $18,37 \%$ possuem mais de 100 programas.

Menor percentual de crescimento entre 1998 e 2014

Medicina III
Ciências Biológicas I $\quad-4,92 \%$

Filosofia/Teologia subcomissão Filosofia

Geociências

Ciências Biológicas II

Medicina II

Odontologia

Nutrição (desde 2010)

Química

Medicina I

$5,56 \%$

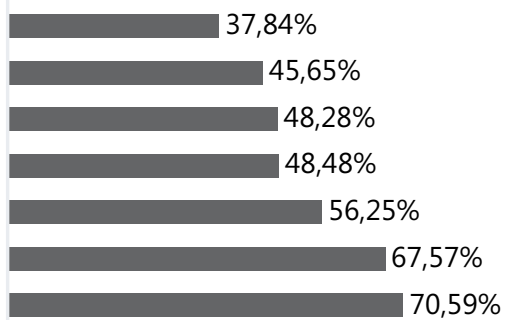

Fonte: GeoCapes (2015).

Figura 3. Áreas com menor percentual de crescimento em número de programas de pós-graduação entre 1998 e 2014. 


\subsection{Vínculos docentes na pós-graduação brasileira: distribuição por áreas do conhecimento de 1998 a 2014}

O número de vínculos docentes retrata o número de professores vinculados a cada programa de pós-graduação nas diversas áreas do conhecimento. Um único docente pode estar vinculado a mais de um programa ao mesmo tempo. No entanto, este indicador apresenta dois períodos de crescimento: o primeiro, findo em 2003 (os docentes eram classificados como Núcleo de Referência Docente ou NRD3, NRD5 e NRD6) e, o segundo, após 2004 (os docentes foram classificados como Permanentes, Colaboradores e Visitantes), quando houve uma redução no número de vínculos devido à mudança na metodologia de contagem de professores atuantes na pós-graduação.

No primeiro período, entre 1998 e 2003 o número de vínculos docentes em programas de pós-graduação, cresceu $47,43 \%$, passando de 58.237 vínculos docentes para 85.857 professores, vinculados em 2003. Analisando o segundo período, ou seja 2004 a 2014, o número de vínculos docentes cresceu 106,09\%, passando de 40.725 para 83.930 vínculos no País. Na Figura 4, observam-se as dez áreas do conhecimento com maior número de vínculos de professores em programas de pós-graduação.

Com 270 programas de pós-graduação, a área Interdisciplinar possui também o maior número de vínculos docentes, 5.675 professores, ou seja, 6,76\% do total de vínculos no Brasil, em média, 21 professores por programa. Em seguida,

Áreas com maior número de vínculos docentes em programas

de pós-graduação em 2014

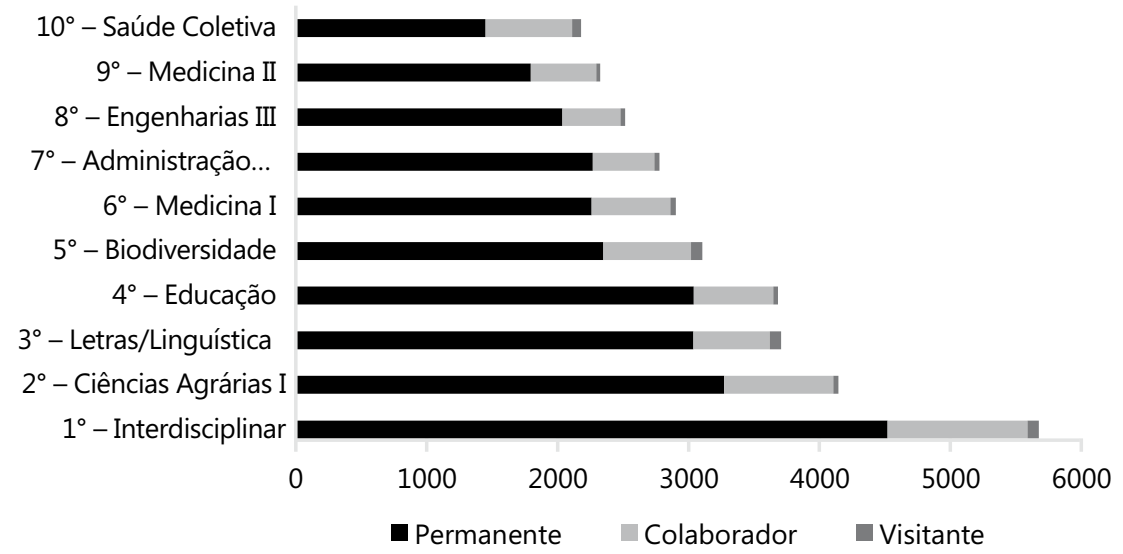

Fonte: GeoCapes (2015).

Figura 4. Áreas com maior número de vínculos docentes na pós-graduação em 2014. 
as Ciências Agrárias I com 214 programas e 4.146 (4,94\%) vínculos docentes ou 19 professores por programa. Letras e Linguística com 3.707 professores para 137 programas, indicando uma média de 27 professores por programa. A área de Educação, com 3.682 ou 4,39\% do total de professores vinculados e 24 professores por programa. Biodiversidade, em quinto lugar no número de vínculos docentes, conta com 3.105 professores para 128 programas, ou 24 professores por programa.

Destoando das demais áreas do conhecimento, Medicina I (sexto lugar) possui 2.902 vínculos docentes distribuídos em 87 programas, perfazendo uma média de 33 professores em cada programa. Seguido da área de Administração, com 2.777 vínculos docentes em 145 programas, caracterizando 19 professores por programa, Engenharias III, com 2.515 professores ou 21 vínculos docentes por programa e Medicina II, com 2.324 professores em 86 programas, uma média de 27 docentes em cada programa.

Na Tabela é disponibilizada a proporção entre o número de docentes vinculados e a quantidade de programas disponíveis em cada área do conhecimento em 2014, visando aprofundar a análise.

Embora não tenha recebido destaque especial no VI PNPG, a área de Filosofia/Teologia: Subcomissão Filosofia conta com maior número de docentes vinculados à pós-graduação. São 44 docentes disponíveis por programa, número acima da média geral entre as áreas do conhecimento, que é de 23 por programa.

As áreas com maior número de docentes vinculados por programa de pós-graduação, como a Filosofia, Astronomia/Física, Química e Medicina I, apresentam vantagens, como a oportunidade de ofertar maior número de disciplinas ou a possibilidade de redução de carga horária dos docentes, priorizando projetos de pesquisa e extensão. Com maior número de docentes, há maior disponibilidade de orientadores, resultando na criação e interação de grupos de pesquisa. Para Ferreira e Pacheco (2009), as novas exigências da Capes quanto à produtividade acadêmica exige mais dos pesquisadores, pois precisam participar de forma ativa e orientar pesquisas em desenvolvimento nos seus "grupos de pesquisa" e atender à "cobrança" por participação no ensino e na extensão, cumprindo os critérios de "impacto e inserção social" em nível nacional e internacional.

Das áreas com menor número de docentes vinculados a programas de pós-graduação em 2014, pode-se citar a Filosofia/Teologia: Submissão Teologia com 300 professores, visto que é a área com menor número de programas no País, apenas 19. Em seguida, Nutrição (criada em 2010), com 458 professores vinculados, possui 25 programas e a área de Serviço Social com 518 vínculos para 31 programas. 
Tabela. Razão entre o número de vínculos docentes e a quantidade de programas disponíveis para cada área em 2014.

\begin{tabular}{llllll}
\hline Proporção entre número de programas e docentes vinculados em todas as áreas (2014) \\
\hline Filosofia/Teologia: & 44 & Direito & 24 & Ensino & 20 \\
Subcomissão Filosofia & 35 & Sociologia & 23 & Arquitetura e Urbanismo & 20 \\
Astronomia/Física & 34 & Geociências & 23 & Medicina III & 20 \\
Química & 33 & Ciências Ambientais & 23 & Ciências Agrárias I & 19 \\
Medicina I & 31 & Artes/Música & 23 & Administração, Ciências & 19 \\
Biotecnologia & 31 & Farmácia & 22 & Engenharias I & 19 \\
Ciências Biológicas II & 30 & Materiais & 22 & Nutrição & 18 \\
Saúde Coletiva & 28 & Geografia & 22 & Psicologia & 18 \\
Matemática & 27 & Engenharias III & 21 & Ciência Política e Relações & 18 \\
Ciências Biológicas I & & Zootecnia/Recursos & 21 & Ciências Sociais Aplicadas & 18 \\
Letras/Linguística & 27 & Pesqueiros & 21 & Economia & 17 \\
Medicina II & 27 & Interdisciplinar & 21 & Serviço Social & 17 \\
Ciências Biológicas III & 27 & Medicina Veterinária & 21 & 17 \\
História & 27 & Enfermagem & 21 & Ciência de Alimentos & 16 \\
Ciência da Computação & 25 & Odontologia & 21 & Planejamento Urbano e & 16 \\
Biodiversidade & & & & Regional/Demografia & \\
Educação & 24 & Educação Física & 21 & Filosofia/Teologia: & 16 \\
Engenharias IV & 24 & Engenharias II & 20 & & \\
\hline
\end{tabular}

Fonte: GeoCapes (2015).

\subsection{Número de discentes na pós-graduação brasileira: distribuição por áreas do conhecimento de 1998 a 2014}

As metas da Capes em elevar o número de doutores no Brasil impactarão diretamente no número de pesquisadores titulados. No período analisado, verifica-se um crescimento no número de mestres e doutores que, entre 1998 e 2014, cresceram 260,31\% e 327,71\%, respectivamente. Em números absolutos, o Brasil passou de 12.351 mestres titulados, em 1998, para 44.502 mestres, em 2014. Já os doutores brasileiros passaram de 3.915 , em 1998, para 16.745 pessoas que receberam o título em 2014. Esta expansão poderá ter como consequência o aumento na qualidade do ensino superior brasileiro, visto que o País terá maior oferta e melhor distribuição dos programas de pós-graduação, conforme previsto nos PNPG, além de aumentar a capacidade tecnológica nacional e os níveis de conhecimento científicos. 
Os dados relativos à formação de mestres e doutores mostram que o Brasil está longe da média mundial, que é de mais de 1.000 pesquisadores para cada milhão de habitantes. Em 2007, o País contava com pouco mais de 500 pesquisadores por milhão de habitantes, segundo o Relatório da Organização das Nações Unidas para a Educação, a Ciência e a Cultura sobre Ciência 2010 (UNESCO, 2010). Conforme dados do GeoCapes (2015), o Brasil possui um doutor para cada 13.109 habitantes, o que não segue a razão proposta pela Organização das Nações Unidas para a educação, a ciência e a cultura (Unesco) de ${ }^{1 /}{ }_{1000}$. A título de comparação, em 2010, a China estava prestes a superar, tanto os EUA quanto a União Europeia, em número de pesquisadores. Cada um desses três países representava cerca de $20 \%$ do contingente mundial de pesquisadores. Em contrapartida, a Índia, um país populoso, tem apenas $2,2 \%$ dos pesquisadores do mundo, enquanto continentes inteiros como América Latina e África têm 3,5\% e $2,2 \%$, respectivamente (UNESCO, 2010).

No Brasil, algumas áreas do conhecimento formaram um maior número de mestres e doutores entre os anos de 1998 e 2014, como mostra a Figura 5.

Os dados corroboram com o exposto pelo VI Plano 2011-2020, em que a maior concentração de discentes por área do conhecimento está nas Ciências Humanas, com um percentual de 17\%. A seguir, estão as áreas de Engenharia, com 15\%; Ciências da Saúde, com 14\%; e as Ciências Sociais Aplicadas, com $12 \%$ dos discentes.

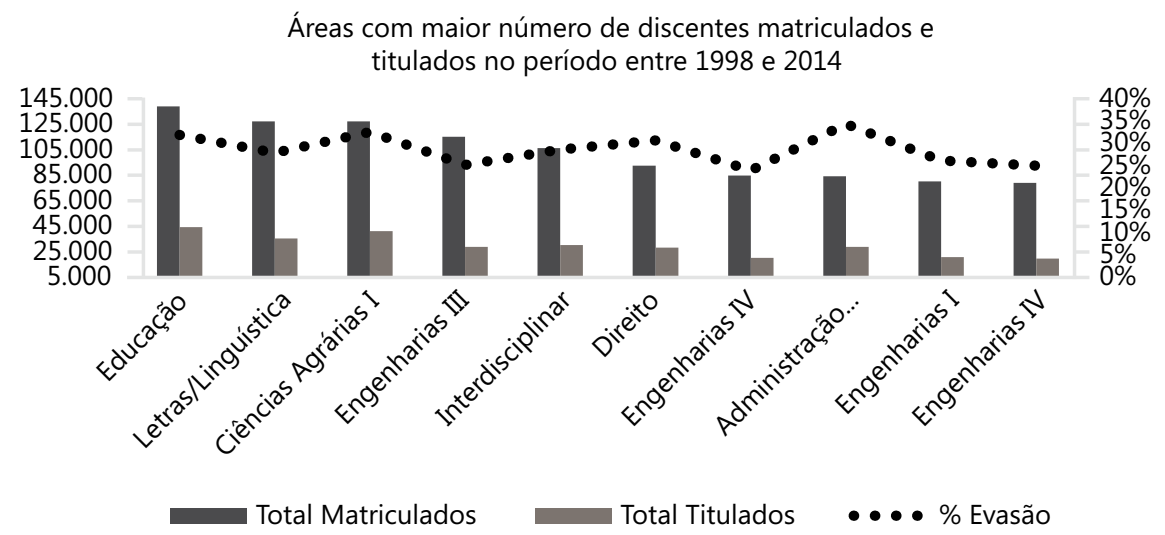

Fonte: GeoCapes (2015).

Figura 5. Áreas com maior número de Discentes Matriculados e Titulados no Brasil no período entre 1998 e 2014. 
No caso das Engenharias, onde a procura pela pós-graduação é menor, o VI Plano expõe esta preocupação quando cita que "[...] essa situação necessita ser alterada no próximo decênio, seja para atender as novas prioridades e ênfases do Plano, seja para fazer face aos desafios e gargalos, sob pena da inviabilização da Agenda Nacional da Pesquisa" (BRASIL, 2010, p. 20), entretanto não são propostas sugestões para esta mudança A taxa de evasão nos programas de pós-graduação se manteve estável, variando entre 23,95\%, dos cursos de Engenharia IV, para a mais alta de $34,34 \%$ referente aos programas de Administração, Ciências Contábeis e Turismo.

As áreas que apresentaram maior formação de Doutores e Mestres no Brasil, no período entre 1998 e 2014, podem ser verificadas nas Figura 6 e 7.

As Ciências Agrárias além de titular o maior número de doutores, também é a segunda área que mais formou mestres. Isso vai ao encontro do VI PNPG, em que se busca, para os próximos anos, dentro do sistema de pós-graduação, a ampliação das políticas, programas e projetos nas Ciências Agrárias, visando a meios sustentáveis para alimentar toda população terrestre nos próximos anos, sem degradar o ambiente. Sendo assim, a Capes cita que os "diferentes Programas de Pós-Graduação em ciências agrárias deverão ajudar a encontrar uma resposta para esta questão pungente" (BRASIL, 2010, p. 19).

A área de Educação é formadora do maior número de mestres e a segunda área com maior índice na formação de doutores entre 1998 e 2014. Ao todo foram 34.340 mestres e 9.427 doutores titulados, em 152 programas de Educação,

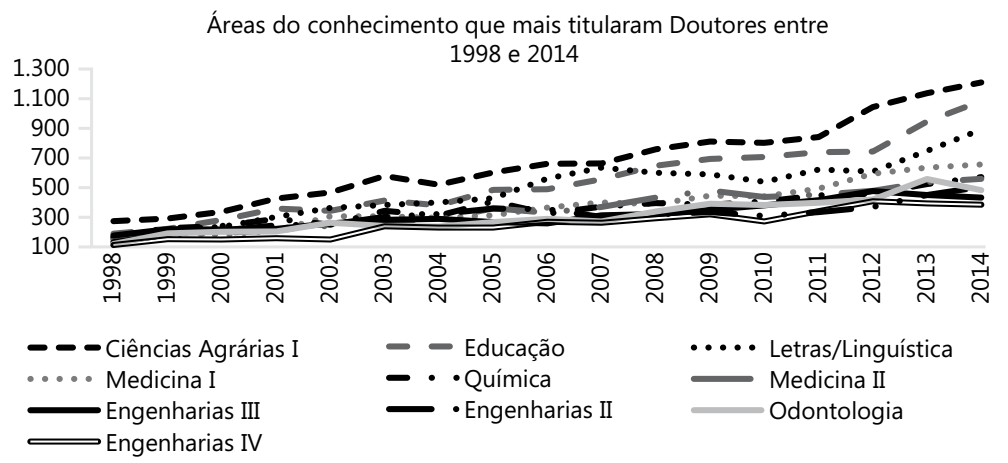

Fonte: GeoCapes (2015).

Figura6. Áreas com maior número de Doutores Titulados no Brasil entre 1998 e 2014. 


\section{Áreas do conhecimento que mais titularam mestres entre}

1998 e 2014

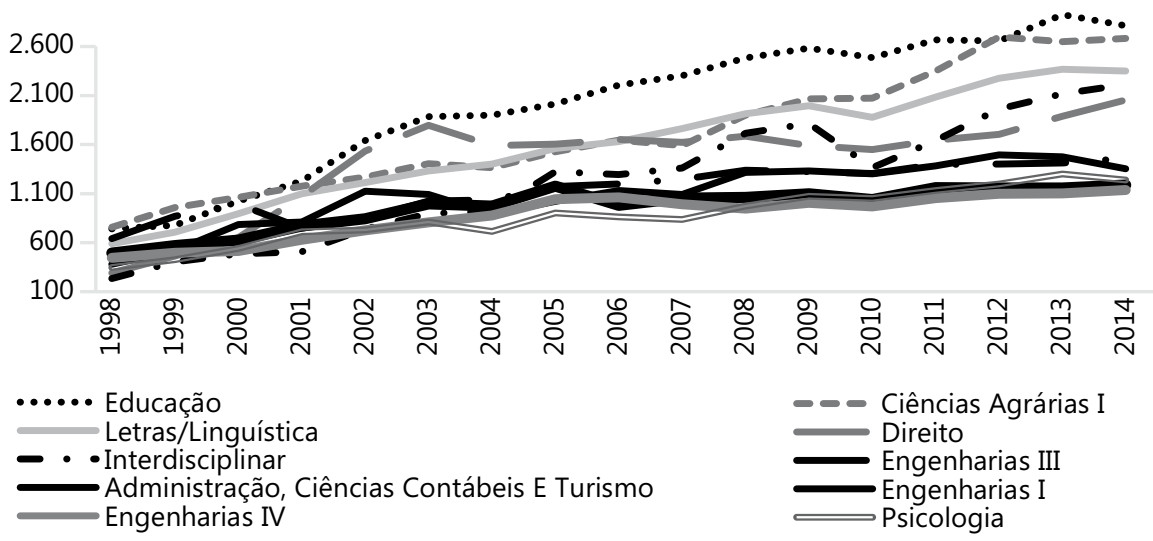

Fonte: GeoCapes (2015).

Figura 7. Áreas com maior número de mestres titulados no Brasil entre 1998 e 2014.

distribuídos pelo País. A área de Educação da Capes é uma das mais numerosas e crescentes. No entanto, no VI Plano 2011-2020, a Capes mostra preocupações, pois apesar de inúmeros cursos de pós-graduação terem dedicado esforços para o estudo e pesquisas relacionadas à educação básica, os resultados são pouco efetivos e visíveis, seja pela amplitude das dificuldades ou pela falta de motivação em tratar de temas ligados às salas de aula.

Ambas as áreas, Educação e Ciências Agrárias, possuem uma quantidade de docentes vinculados à pós-graduação dentro da média geral, que é de 23 docentes por programa. Entre as áreas apresentadas na Figura 6, com maior titulação de doutores, destaca-se a Medicina I, Química e Letras e Linguística, pois estas áreas também possuem maior quantidade de docentes vinculados e, consequentemente, maior disponibilidade para orientação de pesquisas. Já a área de Filosofia/Teologia: subcomissão Filosofia, que contava com uma média de 44 docentes por programa, aparece entre as dez áreas que menos titularam mestres e doutores no País.

\subsection{Investimentos da Capes em bolsas e fomento na pós-graduação brasileira: distribuição de bolsas de estudo no País e bolsistas no exterior por áreas do conhecimento de 1995 a 2014}

Os recursos financeiros da Capes destinados para bolsas de estudos e fomentos cresceram $159,48 \%$ entre 2002 e 2012, saltando de $\mathrm{R} \$ 1.060 .891,83$ para 
$\mathrm{R} \$ 2.752 .749,51$ (valores corrigidos para 2015). Entre 2008 e 2009 os investimentos tiveram seu maior aumento, com pouco mais de $60 \%$. Fato que pode estar relacionado ao crescimento orçamentário que a Capes obteve em 2008. Conforme o PNPG 2011-2020, o orçamento anual da Capes até 2007, destinava-se exclusivamente à pós-graduação, porém, com a aprovação da Lei no 11.502/2007, houve reestruturação das atribuições institucionais e ampliação de sua atuação na educação. Com a atribuição adicional, houve depois de 2008, "um expressivo crescimento orçamentário das ações da pós-graduação, o que foi intensificado pelas novas ações vinculadas às atribuições de melhoria de qualidade do ensino básico" (BRASIL, 2010, p. 258).

A pesquisa científica nacional vem sendo incrementada, entre outros índices, pelo aumento do número de bolsas fornecidas nos últimos anos para a pós-graduação. No Brasil a oferta de bolsas teve um crescimento percentual de $389 \%$, passando de 19.425 bolsas concedidas pela Capes em 1995 para 94.985 bolsas em 2014.

A Figura 8 apresenta as áreas de conhecimento que disponibilizaram o maior número de bolsas de estudo na pós-graduação, considerando o período entre 1995 e 2014.

No período entre 1995 e 2014, as áreas que ofertaram o maior número de bolsas de estudo foram: Ciências Humanas (13.385 bolsas), Ciências da Saúde (13.318 bolsas) e as Ciências Agrárias (12.925 bolsas).

Distribuição de bolsas por grandes áreas do conhecimento entre 1995 e 2014

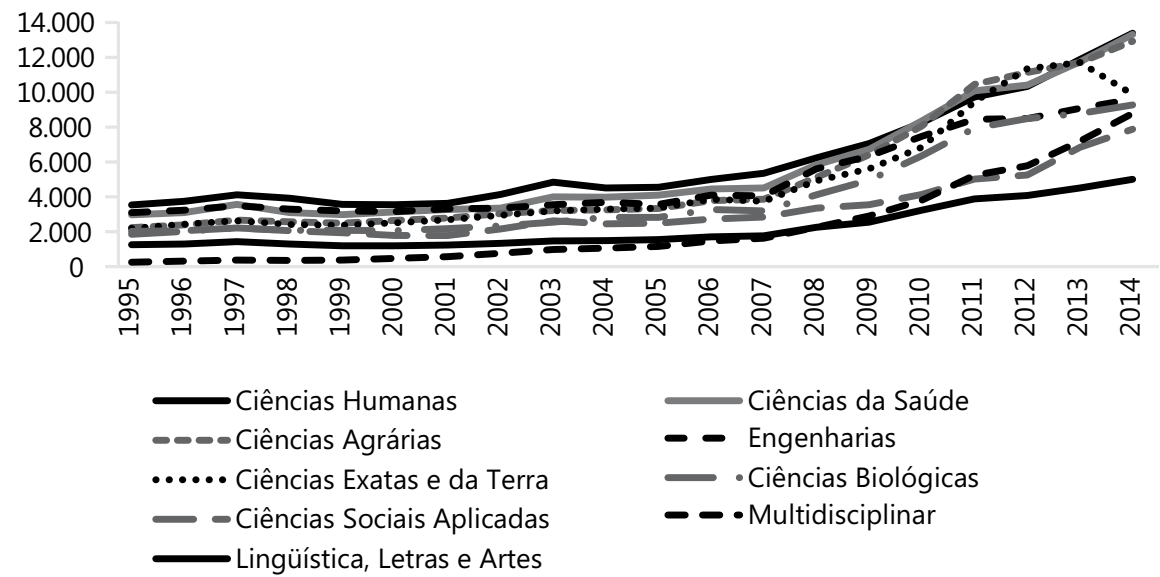

Fonte: GeoCapes (2015).

Figura 8. Distribuição de bolsas de pós-graduação nas grandes áreas do conhecimento entre1995 e 2014. 
Entre as Ciências Humanas, este resultado é consequência da expansão da área de Educação, que é a terceira maior no País. Até o ano de 2014, a área de Humanas contava com 501 programas de pós-graduação, tendo uma média de 26,71 bolsas por programa. A área das Ciências da Saúde, com 586 programas de pós-graduação e uma média de 22,72 bolsas por programa, e as Ciências Agrárias com uma média de 33,22 bolsas para cada um dos 389 programas. A área de Ciências Exatas e da Terra vinha apresentando crescimento constante, porém, em 2014, teve uma queda de $15 \%$ no número de bolsas concedidas.

Entre as áreas com maior crescimento na concessão de bolsas, está a Multidisciplinar, que apresentou 3.400\% de expansão entre 1995 a 2014, seguido pelas Ciências Agrárias, que cresceram $478,30 \%$ no mesmo período.

A área de Letras, Linguística e Artes apresentou o menor número de bolsas concedidas, no entanto, manteve-se dentro da média, com 26,77 bolsas para cada um dos 187 programas de pós-graduação. Destaca-se que esta área é a segunda que mais titulou mestres e doutores no País.

Com relação à distribuição de bolsas de estudo para o Exterior, foram analisadas as bolsas de doutorado, doutorado sanduíche, pós-doutorado, mestrado e mestrado sanduíche. Entre 1998 e 2013, a Capes enviou bolsistas brasileiros para 72 países, em todos os continentes, com exceção da Antártida, num total de 46.848 estudantes, entre mestrandos, doutorandos e pós-doutorandos, mostrando um crescimento de $266,89 \%$.

O continente europeu, com universidades históricas, conservadoras e reconhecidas mundialmente é o destino mais procurado pelos estudantes, com $65,65 \%$ do total de bolsistas. A França é o país europeu com maior número de alunos brasileiros $(19,08 \%)$, Portugal aparece em segundo, com 11,01\%, seguido da Espanha com 9,68\%, Reino Unido e Irlanda do Norte com 9,65\% e Alemanha com 7,89\%. A América é o segundo continente em número de bolsistas brasileiros $(31,74 \%)$ e os EUA aparece como o país que detêm a maior quantidade de estudantes brasileiros, com $24,29 \%$. A Oceania é o terceiro com $1,87 \%$, Ásia com $0,58 \%$ e a África com apenas $0,16 \%$. Segundo Moritz et al. (2013), apesar do aumento do dinamismo político e econômico entre o Brasil e China, percebe-se pouco envolvimento acadêmico com essa região.

Pela Figura 8, nota-se que após 2010 houve um aumento expressivo no número de bolsistas no exterior, possivelmente associado ao lançamento do programa federal Ciência sem Fronteiras, criado em 2011 para incentivar a 
formação acadêmica no exterior, em universidades de excelência. Em nível de pós-graduação, o programa Ciências sem Fronteiras disponibiliza bolsas para mestrado profissional, doutorado sanduíche, doutorado pleno e pós-doutorado.

Na Figura 9 é possível observar as dez áreas com maior número de bolsas de estudo no exterior, que totalizam 46.778 bolsas concedidas entre 1998 e $2013^{2}$.

Letras/Linguística foi a área que mais enviou discentes para universidades do exterior no período mencionado, com $6 \%$ do total de bolsistas. É também a segunda área com o maior número de alunos matriculados na pós-graduação e, desses, 3,38\% tiveram a possibilidade de realizar suas pesquisas em parceria com outros países.

Apesar de a área de Ciências Biológicas II não estar entre as maiores com relação ao número de programas e discentes, é a segunda área do conhecimento que mais enviou bolsistas para o exterior (4,88\%). Em 2013, dos 4.305 alunos matriculados na área, $7,11 \%$ receberam bolsas. Ciências da Computação segue

Áreas com maior número de Bolsas de estudo no Exterior entre 1998 e 2013

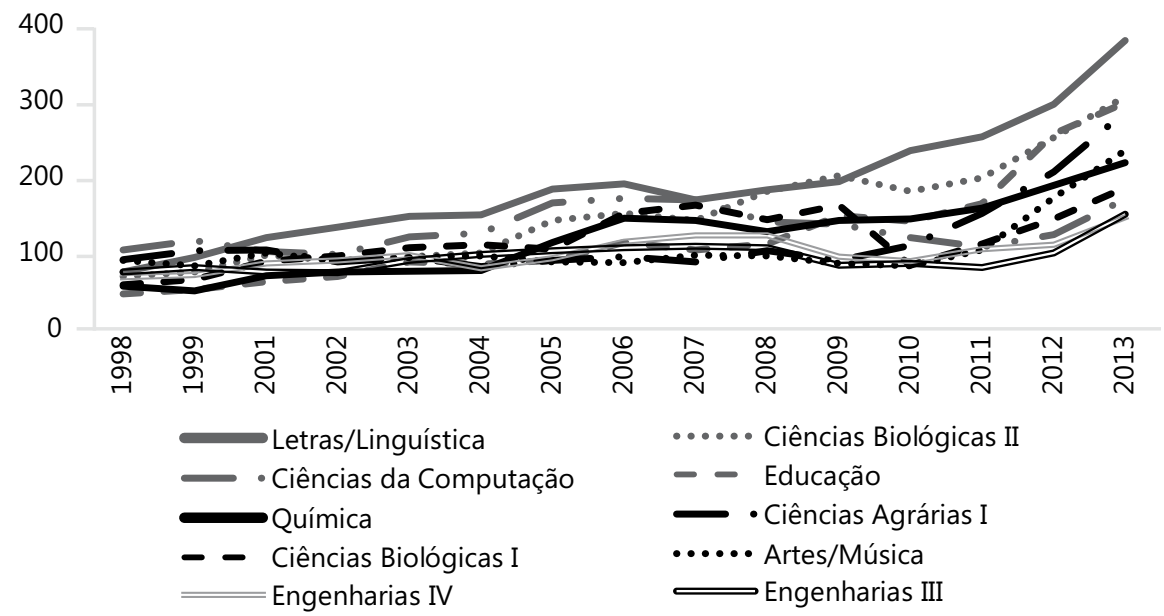

Fonte: GeoCapes (2015).

Figura 9. Distribuição de bolsas no exterior por áreas do conhecimento no período de 1998 a 2013.

\footnotetext{
2 As bolsas concedidas aos estudantes brasileiros no exterior, referentes ao ano 2000, não foram disponibilizadas no GeoCapes, portanto, não foram analisadas no gráfico.
} 
em terceiro lugar com 4,23\% das bolsas no exterior. A área de Educação, que é a primeira em número de discentes titulados, enviou para o exterior $2,38 \%$ dos alunos matriculados na área em 2013.

Com exceção das Ciências Biológicas II (Biofísica, Bioquímica, Farmacologia e Fisiologia) nenhumas das outras áreas demonstradas na Figura 9 estão listadas no último Plano como áreas prioritárias para o desenvolvimento do País. De acordo com o que foi proposto no VI PNPG 2011-2020, a Capes visa estimular parcerias e formação de redes de pesquisa com universidades internacionais em áreas consideradas prioritárias, como as Engenharias e as Ciências da Saúde, visto que o foco deste decênio seria o fomento à infraestrutura tecnológica, biotecnologia, medicamentos e produção de vacinas.

As bolsas de estudo no exterior contribuem de forma ímpar com a formação altamente qualificada, com competências e habilidades necessárias para o avanço do conhecimento nacional em parceria com instituições de excelência no exterior.

\section{Considerações finais}

Nos quase 20 anos de pós-graduação avaliados neste estudo, denotam-se implementações significativas, como políticas e projetos que visam a avanços da produção científica e tecnológica no País, especialmente em algumas áreas do conhecimento. No entanto, o sistema de pós-graduação stricto sensu brasileiro é apenas a ponta do iceberg de todo o sistema educacional que revela, de forma pouco nítida e questionável, a ineficiência de alguns procedimentos e propostas apresentadas por meio dos PNPG.

Com relação a (1) distribuição dos programas de pós-graduação por área do conhecimento entre 1998 e 2014, é possível inferir que as áreas que apresentaram o maior número de programas de pós-graduação foram: Interdisciplinar (270 programas de pós-graduação), Ciências Agrárias I (214) e a área de Educação (152). No entanto, as áreas que apresentaram o maior percentual de crescimento nesse período foram as de Ensino (5.250\%), Biodiversidade (884\%) e a Interdisciplinar (694\%).

Sobre a (2) distribuição de vínculos docentes da pós-graduação por área do conhecimento, observou-se que o Brasil encerrou o ano de 2014 com um total de 83.930 docentes vinculados aos programas de pós-graduação nacionais, o que representa uma média de 22 docentes por programa. Destacam-se as três maiores áreas com relação à variável vinculo docente: Interdisciplinar (6,76\%), com 
média de 21 docentes por programa; Ciências Agrárias I (4,94\%), 19 docentes por programa e Letras/Linguística (4,42\%), com 27 docentes por programa, em média.

Avaliando a proporção entre vínculos docentes e a quantidade de programas de pós-graduação, infere-se que a área de Filosofia/Teologia: Submissão Filosofia apresenta a maior proporção, com 44 professores vinculados por programa de pós-graduação.

Quanto à (3) distribuição de discentes na pós-graduação e o número de mestres/doutores em cada área do conhecimento, destacam-se as áreas de Educação, Letras/Linguística e as Ciências Agrárias, que possuem o maior número de alunos matriculados e titulados entre todas as áreas. As áreas do conhecimento com maior titulação de doutores no período analisado, foram: Ciências Agrárias (7,35\%); Educação (6,59\%) e Letras/Linguística (5,52\%). Com relação ao número de mestres titulados, Educação aparece em primeiro (6,32\%), Ciências Agrárias I (6,03\%) em segundo e, em terceiro, Letras/Linguística $(5,29 \%)$.

Os (4) investimentos realizados pela Capes em bolsas (no Brasil e no exterior) em cada área do conhecimento, no período entre 1995 e 2014, foram majoritários nas áreas de Ciências Humanas (121.319 bolsas ou 15,24\%), Ciências da Saúde (112.949 bolsas ou 14,19\%) e Ciências Agrárias (104.091 bolsas ou 13,08\%).

Em geral, os investimentos da Capes destinados a bolsas de estudos cresceram $159,48 \%$ entre 2002 e 2012 , saltando de $\mathrm{R} \$ 1.060 .891,83$ para $\mathrm{R} \$ 2.752 .749,51$ (valores corrigidos para 2015). Os investimentos em bolsas de estudo no exterior até o ano de 2012 representavam apenas $0,45 \%$ ou $\mathrm{R} \$ 9.636,32$ do montante destinado a bolsas de estudo. No entanto, a oferta de bolsas de estudo para brasileiros no exterior teve um crescimento de $178 \%$ entre 1998 e 2012. A circulação de pessoas no exterior auxilia na internacionalização das pesquisas brasileiras, embora, em 2012, apenas 4.213 (2,98\%) do total de pesquisadores tiveram acesso a bolsas de estudo no exterior.

Embora essa pesquisa tenha demonstrado um crescimento significativo no número de programas, de docentes e discentes nas áreas de Humanas (Educação, Ensino e Letras), pesquisas realizadas por Almeida e Guimarães (2013) mostraram que o crescimento das publicações científicas, no Brasil, ainda é subscrito por áreas mais consolidadas, como a Física, Medicina, Química e Ciências Biomédicas que, juntas, representam cerca de $70 \%$ da produção nacional. Segundo esses autores, as Ciências Humanas apresentam baixa visibilidade no cenário mundial. Isso pode estar associado ao fato que, de forma geral, os pesquisadores brasileiros das 
áreas de Ciências Sociais e Humanas tendem a publicar principalmente livros, enquanto que, nas Ciências Exatas, Biologia, Medicina e Agricultura, os artigos científicos são a forma predominante de publicação.

De 1995 a 2014, o sistema de pós-graduação passou por incrementos, implementações e alterações que geraram crescimento no número de programas de pós-graduação, número de vínculos docentes, formação discente em pós-graduação e concessão de bolsas de estudos, tanto no Brasil quanto no exterior.

No entanto, mesmo que os números mostrem percentual de crescimento, será que é ousado dizer que o País entra em um período de estagnação? Esta pesquisa não tem dados empíricos para sustentar uma resposta categórica, mas há indícios ou evidências para afirmar que o Brasil inicia um período de recessão na pós-graduação, principalmente no que tange aos investimentos realizados pela Capes em bolsas (no Brasil e no exterior) e abertura de novos programas de pós-graduação em distintas áreas do conhecimento, sendo o aprofundamento dessa indagação uma sugestão para pesquisas futuras. 


\title{
Fields of knowledge in graduate courses in Brazil: longitudinal growth from 1995 to 2014
}

\begin{abstract}
The main objective of this research was measuring the growth of fields of knowledge in national graduate courses from 1995 to 2014. Data were collected out of the Systems of Geo-referenced information of Capes (GeoCapes). The following variables were used as variables of research: (i) distribution of graduate programs by field of knowledge; (ii) distribution of graduate courses teachers; (iii) distribution of students; (iv) investment on scholarship and development. The results show that the fields of knowledge that presented the highest number of graduate courses were Interdisciplinary, Agricultural Science and Education. The fields with highest percentages of growth were Education, Biodiversity and Interdisciplinary. Fields like Medicine III and Biological Science had their number of programs reduced. Philosophy, Astronomy and Chemistry showed the highest number of teachers connected to graduate programs; however, they did not train the largest number of masters and doctors.
\end{abstract}

Keywords: Graduate program. Knowledge field. Teachers and graduate student.

\section{Los campos de conocimiento en postgrado en Brasil: crecimiento longitudinal entre 1995 y 2014}

\section{Resumen}

El objetivo de esta investigación fue medir el crecimiento de los campos de conocimiento en el posgrado en Brasil entre 1995 y 2014. Los datos fueron recogidos en el Sistema de Información Georreferenciadas de la Capes (GeoCapes). Fueron utilizadas como variables de estudio (i) la distribución de los programas de postgrado por campos de conocimiento; (ii) la distribución de los docentes de posgrado; (iii) la distribución de los estudiantes; (iv) las inversiones en becas y financiación. Los resultados muestran que los campos de conocimiento con mayor número de programas de posgrado fueron Interdisciplinario, Ciencias Agrícolas y Educación. Los campos con mayor crecimiento porcentual fueron Educación, Biodiversidad e Interdisciplinario. Campos como Medicina III y Ciencias Biológicas tuvieron reducción en el número de programas. Filosofía, Astronomía y Química tienen el mayor número de profesores vinculados por programa de posgrado; sin embargo, ellos no forman el mayor número de magísteres y doctores.

Palabras clave: Programas de postgrado. Campos de conocimiento. Profesores y estudiantes de postgrado. 


\section{References}

ALMEIDA, E. C. E.; GUIMARÃES, J. A. Brazil's growing production of scientific articles: how are we doing with review articles and other qualitative indicators? Scientometrics, v. 97, n. 2, p. 287-315, Nov. 2013. doi:10.1007/s11192-013-0967-y

AVILA, A. B.; RAUPP, M. D.; MORAES, M. C. M. A (in)existência do IV plano nacional de pós-graduação. In: ALMEIDA, M. L. P.; MENDES, V. H. (Org.). Educação e racionalidade: questões de ontologia e método em educação. Campinas: Mercado das Letras, 2009. p. 197-210.

BALBACHEVSKY, E. A pós-graduação no Brasil: novos desafios para uma política bem-sucedida. SCHWARTZMAN, S.; BROCK, C. Os desafios da educação no Brasil. Rio de Janeiro: Nova Fronteira, 2005. p. 285-314.

BARRETO, F. C. S.; BORGES, M. N. Novas políticas de apoio à pós-graduação: o caso FAPEMIG-CAPES. Ensaio: Avaliação e Políticas Públicas em Educação, v. 17, n. 65, p. 599-612, out./dez. 2009. doi:10.1590/S0104-40362009000400003

BOMENY, H. Newton Sucupira e os rumos da educação superior. Brasília, DF: Paralelo 15, 2001. (Série Paralelo, 15).

BRASIL. Ministério da Educação. Coordenação de Aperfeiçoamento de Pessoal de Nível Superior. Plano Nacional de Pós-Graduação (PNPG) 2005-2010). Brasília, DF: CAPES, 2005.

. Ministério da Educação. Coordenação de Aperfeiçoamento de Pessoal de Nível Superior. Plano Nacional de Pós-Graduação (PNPG) 2011-2020. Brasília, DF: CAPES, 2010.

BRASIL. Ministério da Educação. Coordenação de Aperfeiçoamento de Pessoal de Nível Superior. Diretoria de Avaliação. Documento de Área 2013: Área de avaliação: Administração, ciências contábeis e turismo. Brasília, DF: CAPES, 2013d. Disponível em: <https://www.capes.gov.br/images/stories/ download/avaliacaotrienal/Docs_de_area/Administra\%C3\%A7\%C3\%A3o doc_area_e_comiss\%C3\%A3o_16out.pdf>. Acesso em: 6 jun. 2016

. Ministério da Educação. Coordenação de Aperfeiçoamento de Pessoal de Nível Superior. Diretoria de Avaliação. Documento de Área 2013: Área de avaliação: Biodiversidade. Brasília, DF: CAPES, 2013c. Disponível em: $<$ www.capes.gov.br/images/stories/download/avaliacaotrienal/Docs_de_area/ Biodiversidade_doc_area_e_comissão_block.pdff $>$. Acesso em: 6 jun. 2016 . 
BRASIL. Ministério da Educação. Coordenação de Aperfeiçoamento de Pessoal de Nível Superior. Diretoria de Avaliação. Documento de Área 2013: Área de avaliação: Ciências biológicas I. Brasília, DF: CAPES, 2013f. Disponível em https://www.capes.gov.br/images/stories/download/ avaliacaotrienal/Docs_de_area/Ciencias_Biologicas_I_doc_area_e_ comiss\%C3\%A3o_block.pdf>. Acesso em: 6 jun. 2016.

. Ministério da Educação. Coordenação de Aperfeiçoamento de Pessoal de Nível Superior. Diretoria de Avaliação. Documento de Área 2013: Área de avaliação: Ensino. Brasília, DF: CAPES, 2013b. Disponível em: $<$ http://ppgect.ufsc.br/files/2013/09/Documento-de-Area-Ensino-Trienal-2013. pdf $>$. Acesso em: 6 jun. 2016.

Ministério da Educação. Coordenação de Aperfeiçoamento de Pessoal de Nível Superior. Diretoria de Avaliação. Documento de Área 2013: Área de avaliação: Filosofia. Brasília, DF: CAPES, 2013g. Disponível em http://www.capes.gov.br/images/stories/download/ avaliacaotrienal/Docs_de_area/Filosofia_Teologia_doc_area_e_ comiss\%C3\%A3o.pdf >. Acesso em: 6 jun. 2016.

. Ministério da Educação. Coordenação de Aperfeiçoamento de Pessoal de Nível Superior. Diretoria de Avaliação. Documento de Área 2013: Área de avaliação: Interdisciplinar. Brasília, DF: CAPES, 2013a. Disponível em $<$ http://www.capes.gov.br/images/stories/download/avaliacaotrienal/Docs_ de_area/Interdisciplinar_doc_area_e_comiss\%C3\%A3o_ATT27SET.pdf $>$. Acesso em: 6 de jun. 2016. g

Ministério da Educação. Coordenação de Aperfeiçoamento de Pessoal de Nível Superior. Diretoria de Avaliação. Documento de Área 2013: Área de avaliação: Medicina III. Brasília, DF: CAPES, 2013e. Disponível em: <https://www.capes.gov.br/images/stories/download/avaliacaotrienal/ Docs_de_area/Medicina_III_doc_area_e_comiss\%C3\%A3o_att08deoutubro. pdf $>$. Acesso em: 6 jun. 2016.

. Ministério da Educação. Coordenação de Aperfeiçoamento de Pessoal de Nível Superior. Sobre a avaliação. CAPES, 2016. Disponível em: $<$ http://www.capes.gov.br/avaliacao/sobre-a-avaliacao $>$. Acesso em: 6 jun. 2016.

. Ministério da Educação. Fundação Coordenação de Aperfeiçoamento de Pessoal de Nível Superior. Portaria n ${ }^{\circ}$ 80, de 16 de dezembro de 1998. Dispõe sobre o reconhecimento dos mestrados profissionais e dá outras providências. Diário Oficial da União, 17 dez. 1998. 
BRASIL. Ministério da Educação. Fundação Coordenação de Aperfeiçoamento de Pessoal de Nível Superior. Resolução $n^{\circ} 5$, de 11 de dezembro de 2014. Avaliação do Sistema Nacional de Pós-Graduação (SNPG). 2014. Disponível em: <https://www.capes.gov.br/images/stories/ download/avaliacao/legislacao/1412015-resolucao-n-5-de11122014.pdf>. Acesso em: 6 jun. 2016.

. Senado Federal. Parecer CFE no 977/65, aprovado em 3 dez. 1965. Revista Brasileira de Educação, n. 30, p. 162-73, set./dez. 2005. doi:10.1590/S1413-24782005000300014

FERREIRA, N. S. C.; PACHECO, J. A. As políticas de formação de pesquisadores: análise comparativa (Portugal-Brasil) em contextos de programas de pós-graduação. Ensaio: Avaliação e Políticas Públicas em Educação, v. 17, n. 65, p. 719-28, out./dez. 2009. doi:10.1590/S0104-4036200900040000

GEOCAPES. Sistema de Georreferências da Capes. Brasília, DF: Capes, 2015. Disponível em: <http://geocapes.capes.gov.br/geocapes2/>. Acesso em: 6 jun. de 2016

GUZZO, R. S. L. et al. Perspectives and challenges regarding Brazilian policies for research and postgraduate studies in psychology. Psicologia: Reflexão e Crítica, v. 28, supl 1, p. 34-9, 2015. doi:10.1590/1678-7153.2015284006

HOSTINS, R. C. L. Os Planos Nacionais de Pós-graduação (PNPG) e suas repercussões na pós-graduação brasileira. Perspectiva, v. 24, n. 1, p. 133-60, 2006.

KUENZER, A. Z.; MORAES, M. C. M. Temas e tramas na pós-graduação em educação. Educação \& Sociedade, v. 26, n. 93, p. 1341-62, set./dez. 2005. doi:10.1590/S0101-73302005000400015

LEITE, M. Em 20 anos, País vai de $24^{\circ}$ a $13^{\circ}$ em ranking de pesquisa. Folha de São Paulo, 1 nov. 2014. Disponível em: <http://www1.folha.uol.com.br/ ciencia/2014/11/1541834-em-20-anos-pais-vai-de-24-a-13-em-ranking-depesquisa.shtml>. Acesso em: 6 jun. 2016.

MORITZ, G. O. et al. A pós-graduação brasileira: evolução e principais desafios no ambiente de cenários prospectivos. Future Studies Research Journal: Trends and Strategies, v. 5, n. 2, p. 3-34, jul./dez. 2013. 
UNESCO. Relatório Unesco sobre ciência 2010: o atual status da ciência em torno do mundo: resumo executivo. Brasília, DF: Unesco, 2010.

\section{Informações dos autores:}

Caroline Lievore: Mestre em Engenharia de Produção e Doutoranda em Ensino de Ciência e Tecnologia - PPGECT pela Universidade Tecnológica Federal do Paraná - UTFPR. Contato: carolievore1@gmail.com

Claudia Tania Picinin: Doutora em Administração. Professora da Universidade Tecnológica Federal do Paraná - UTFPR. Contato: claudiapicini@utfpr.edu.br

Luiz Alberto Pilatti: Doutor em Educação Física. Bolsista de Produtividade em Pesquisa. Professor Titular e Reitor da Universidade Tecnológica Federal do Paraná - UTFPR. Contato: lapilatti@utfpr.edu.br 